\title{
GOBERNANZA Y REALIDADES ELECTORALES EN MARRUECOS: LAS LEGISLATIVAS DE 2007
}

AMINA EL MESSAOUDI 
SUMARIO

INTRODUCCIÓN. I. GOBERNANZA ELECTORAL. 1. Los desafíos del nuevo dispositivo electoral. 2. La nueva norma de partidos. 3. Prácticas institucionales reconfortantes. A. La cuota de mujeres. B. Control y observación electoral. II. REALIDADES ELECTORALES. 1. El giro inesperado. 2. Ambigüedad del paisaje político. 3. La abstención. BIBLIOGRAFÍA. 


\title{
GOBERNANZA Y REALIDADES ELECTORALES EN MARRUECOS: LAS LEGISLATIVAS DE 2007
}

\author{
POR \\ AMINA EL MESSAOUDI ${ }^{1}$ \\ Catedrática de Derecho Constitucional \\ Universidad Mohamed V. Rabat-Agdal
}

\section{INTRODUCCIÓN}

El 7 de septiembre de 2007, Marruecos organizó las octavas elecciones legislativas desde su independencia para elegir los trescientos veinte y cinco diputados de la Cámara de Representantes². Tras las reformas electorales de 2002,

1 Catedrática de Derecho Constitucional de la Universidad Mohamed V, Rabat, Facultad de Ciencias Jurídicas, Económicas y Sociales, Departamento de Derecho Público y Ciencia Política. Es autora de varias publicaciones en libros, libros colectivos y revistas sobre la vida constitucional y política en Marruecos y en derecho comparado.

* Quiero agradecer la lectura de estas páginas así como los comentarios enriquecedores de Abdellah Saaf y de María Angustias Parejo.

2 Además de la página web del Ministerio del Interior marroquí sobre las elecciones de 2007 (www.gov.elections2007.ma), existe una abundante literatura en árabe y en francés relacionada con dichas elecciones legislativas del 7 de marzo de 2007. Para más información, en español, sobre el conjunto de las elecciones marroquíes, véanse: Bernabé López García, 2000: Marruecos político (cuarenta años de procesos electorales 1960-2000), CIS, Colección Monografías. n. ${ }^{\circ}$ 176, Madrid; Juan Montabes Pereira, 1999: Las otras elecciones, los procesos y sistema electorales en el Magreb, AECI, Madrid; María Angustias Parejo Fernández, 1999: «El proceso electoral como indicador privilegiado de la transición tutelada en Marruecos» en Miscelánea de Estudio árabes y hebráicos. Sección Árabe-Islam. Vol. 48, Universidad de Granada, pp. 271-296. 
en las segundas elecciones legislativas del nuevo régimen, se producen importantes modificaciones del dispositivo jurídico preelectoral. Marruecos se enfrenta al reto de instaurar una "gobernanza» o «engennering» para el escrutinio del 7 de septiembre, que debe dar respuesta a un gran número de cuestiones que habían suscitado un intenso debate político ${ }^{3}$.

De hecho, tras las diversas consultas entre el gobierno y los partidos políticos, parece que se consolida el gran debate político e institucional sobre el marco normativo electoral, que ya había surgido en las elecciones de $2002^{4}$, y que afecta a otros aspectos en vísperas del escrutinio que debía permitir el desarrollo de la octava experiencia electoral en Marruecos.

El segundo escrutinio del tercer milenio, que tiene lugar de conformidad con nuevos aspectos reglamentarios y legislativos, se presenta como un momento decisivo hacia la instauración de nuevos mecanismos que permitan gestionar mejor el proceso electoral.

En este artículo, mi objetivo consiste en analizar, en un primer momento, el impacto de la nueva norma electoral en la gobernanza del escrutinio del 7 de septiembre de $2007^{5}$. En segundo lugar, compararé las nuevas prácticas jurídicas con las realidades electorales del terreno político marroquí, para aprehender las dinámicas de continuidad o de transformación que éstas suponen.

Sin duda, una rápida observación del terreno político marroquí permite atisbar fácilmente cuáles son los temas que caracterizaron la legislatura de 20022007 y que estuvieron directamente relacionados con las elecciones de 2007: la ley de partidos políticos, el Código Electoral, en especial, la Ley Orgánica rela-

3 Partiendo del informe del Banco mundial, 2003 sobre buena governanza en el medio oriente y el norte de Africa, (Better Goernance for Development in the Middle East and North Africa. Enhancing Inclusiveness and Accountability), entiendo, en este trabajo, con el término «buena gobernanza» ciertos procesos políticos y normativos que se llevan a cabo en Marruecos con el fin de permitir el desarrollo transparente y democrático del proceso electoral.

${ }^{4}$ Las nuevas disposiciones previas al voto de 2002 consistían en la modificación de la Ley Orgánica relativa a la elección de los miembros de la Cámara de Representantes, modificaciones que introdujeron un nuevo modo de escrutinio, el reparto de escaños en listas locales y nacionales. Para más detalles sobre las elecciones legislativas de 2002, véase: El Messaoudi Amina, 2002: «Nouveau cadre normatif et «assainissement» électoral. Élections 2002». Annuaire de l'Afrique du Nord. CNRS. pp. 325-336.

5 El impacto del nuevo dispositivo electoral sobre el proceso de las elecciones de 2007 en Marruecos, fue objeto de mi comunicación presentada en la sesión plenaria titulada: «Elecciones, poder, legitimidad. El impacto interno y regional de las elecciones en Palestina, Líbano, Argelia, Marruecos y Turquía», en el marco de la Conferencia anual de EuroMESCo bajo título: "Una agenda común frente a la intolerancia. Los derechos humanos como interés común», 3 y 4 de octubre de 2007 en Lisboa. 
tiva a la elección de los miembros de la Cámara de Representantes y, sobre todo, el impacto de la decisión del Consejo Constitucional que fomenta, a la vez, el pluralismo y la normalización de partidos.

Por lo tanto, si el cambio normativo introducido en 2002 pretendía sanear el sistema electoral, el de 2007 pretende favorecer la racionalización y la «normalización» del terreno político.

De hecho, es importante recordar que este objetivo que aparece en numerosas ocasiones en los discursos del soberano marroquí, también se destacaba en los discursos de Hassan II a finales de los años noventa. En el discurso del 8 de octubre de 1996 que precedió a las elecciones legislativas de junio de 1997, el soberano puso de relieve la necesidad de modernizar el terreno político mediante una posible polarización, especialmente, en dos o tres grandes bloques que se alternaran para gestionar los asuntos públicos.

Paralelamente al debate sobre las reformas del Código Electoral, el llamamiento a la transparencia de las elecciones y su autenticidad son las principales características de la movilización del Estado y de la sociedad civil. De hecho, el Rey Mohamed VI destacó, en numerosas ocasiones, que las elecciones de 2007 representarían una nueva etapa para la consagración del proceso de democratización y la construcción del Estado de Derecho e, incluso, solicitó a todas las partes que se implicaran para que esta consulta fuera transparente y se inscribiera en la más absoluta normalidad.

Por ello, entre las técnicas y procedimientos empleados para sanear el sistema electoral, cabe destacar la movilización de la sociedad civil en su totalidad, para sensibilizar sobre la importancia de ejercer el voto. Asimismo, en la misma línea se inscriben las actuaciones de colaboración y de coordinación entre los ministerios de Interior y Justicia a través de la Comisión Electoral Conjunta, encargada del seguimiento de las denuncias relativas a las irregularidades electorales.

No obstante, si las elecciones del 7 de septiembre parecían aportar elementos que facilitaran la instauración de una cierta gobernanza electoral (I), los resultados de las elecciones, en especial la baja tasa de participación, junto con otras realidades electorales, demuestran la existencia de desencanto y de desilusión en el electorado marroquí (II).

\section{GOBERNANZA ELECTORAL}

En ciencia política, la gobernanza se define como un proceso de coordinación de actores, de grupos sociales, de instituciones, para lograr los objetivos propios discutidos y definidos, de manera colectiva, en entornos fragmentados e in- 
ciertos. La gobernanza remite, por lo tanto, a un conjunto de instituciones, de redes, de directivas, de reglamentaciones, de normas, de usos políticos y sociales, de actores públicos y privados que contribuyen a la estabilidad de una sociedad y de un régimen político, así como a su orientación, a la capacidad de dirigir, a la capacidad de proporcionar servicios y asegurar su legitimidad ${ }^{6}$.

El conjunto de prácticas adoptadas por los actores políticos y sociales en Marruecos en la víspera de las elecciones del 7 de septiembre, se concretiza en los nuevos ajustes del Código Electoral (1), en la joven norma de partidos (2) y en la conservación de ciertas prácticas institucionales (3).

\section{Los desafíos del nuevo dispositivo electoral}

La elección de los miembros de la Cámara de Representantes que iban a ocupar un escaño en el Parlamento durante la octava legislatura (2007-2012) tenía que realizarse de conformidad con un sistema de votación proporcional de listas siguiendo la fórmula del remanente. En 2002, este sistema substituyó el escrutinio uninominal mayoritario ${ }^{7}$.

Si el modo de escrutinio adoptado por primera vez en $2002^{8}$ se mantuvo durante los comicios del 7 de septiembre de 2007, a las condiciones establecidas para el reparto de escaños se le aplicaron, sin embargo, las modificaciones reclamadas por los partidos de la mayoría gubernamental tras un largo debate coronado por la decisión del Consejo Constitucional.

Por lo tanto, el Consejo Constitucional confirmó su propia jurisprudencia de 2002 y declaró que la disposición relativa al umbral de 6\% exigido en las elecciones para tener acceso al reparto de escaños, de acuerdo con la Constitución. Esta decisión, a la vez que apoya la existencia de partidos, admite que di-

6 Williamson, O; 1996: The mechanisms of governance, Oxford, Oxford University Press.

${ }^{7}$ La nueva disposición del artículo primero de la Ley Orgánica relativa a la elección de los miembros de la Cámara de Representantes es la siguiente: «La Cámara de Representantes se compone de 325 miembros elegidos por sufragio universal directo mediante el sistema de listas en las condiciones siguientes: 295 miembros son elegidos en las circunscripciones electorales creadas de conformidad con las disposiciones del artículo 2 que consta a continuación. 30 miembros son elegidos a escala nacional. El escrutinio da lugar a la representación proporcional siguiendo la fórmula de los remanentes sin combinaciones ni voto preferencial». Ley Orgánica n. ${ }^{\circ}$ 06-02, Boletín Oficial n. 5018 del 4-7-2002. pp. 709-713.

${ }^{8}$ La introducción, por primera vez en 2002, del escrutinio proporcional de listas cerradas, se aplicó también en 2003 durante las elecciones municipales, en las ciudades de más de 25.000 habitantes (los municipios más pequeños conservan la división en circunscripciones uninominales). 
cho umbral conlleva una obligación de resultado a la hora de comprometer a una fuerza política en la responsabilidad de la representación nacional. De este modo, se logra introducir un cierto orden en la lucha política marroquí. ¿No forma parte esta decisión de la lógica política más habitual en democracia? El umbral de $6 \%$ se sitúa al nivel de los umbrales estándares en derecho electoral comparado?.

Sin embargo, el Consejo invalidó la disposición del proyecto de ley que reformaba el Código Electoral excluyendo del derecho a la candidatura a los partidos que hubieran recibido menos del $3 \%$ de los sufragios expresados en las elecciones de 2002, ya que consideró que esta disposición representaba un ataque a la igualdad entre los partidos políticos.

Aunque parece que los criterios en los que basó su decisión el Consejo Constitucional para rechazar el umbral del $3 \%{ }^{10}$ fueron la igualdad entre los partidos y la libre competencia política, el conservar el umbral del 6\% para la distribución de los escaños ${ }^{11}$ parece que tiene como objetivo hacer frente a la desintegración del campo político y a su fragmentación (treinta y un partidos compitieron en las elecciones del 27 de septiembre de 2002, treinta y tres a las del 7 de septiembre de 2007 frente a sólo dieciocho en 1997). En términos concretos, esto quiere decir que toda lista que no consiga un mínimo del 6\% de los votos en juego, queda eliminada de oficio del reparto de los escaños. Varios partidos políticos exigieron que dicho umbral se redujera, al menos, al $5 \%$ ya que ésta es la cifra que toma la Ley de Partidos en relación a las subvenciones estatales.

Inicialmente, el Proyecto de Ley $22-06^{12}$ preveía un umbral del 7\%. E incluso con un umbral del $6 \%$, los sectores femeninos de varios partidos protestaron porque consideraban que una disposición de ese tipo favorecería a tres o cuatro partidos en detrimento de la abrumadora mayoría.

9 El umbral es de $10 \%$ de los sufragios expresados para obtener un escaño en el parlamento turco, del $5 \%$ para obtener un escaño en el parlamento alemán, español y belga y sólo del 3\% para el parlamento sueco.

${ }^{10}$ Decisión n. $^{\circ}$ 603-07 de 23 de enero de 2007, Boletín Oficial n. ${ }^{\circ} 5498$ de 8 de febrero de 2007, p. 586.

${ }_{11}$ Antes de la modificación de la Ley Orgánica relativa a la elección de los miembros de la Cámara de Representantes, el umbral era de sólo un 3\% (art. 79 de la Ley Orgánica).

${ }^{12}$ La Cámara de Representantes adoptó dos proyectos de ley: el proyecto de ley n.o 22-06 que modifica y completa la Ley Orgánica n. ${ }^{\circ}$ 31-97 relativa a la elección de los miembros de la Cámara de Representantes B.O. n. ${ }^{\circ} 5514$ de 05-04-2007, p. 448 así como el Proyecto de Ley no 23-06 que modifica y completa la ley n. ${ }^{\circ}$ 9-97 sobre el Código Electoral. La adopción se llevó a cabo por 102 votos a favor, 27 en contra y 10 abstenciones. 
De hecho, los resultados de los comicios del 7 de septiembre de 2007 demostraron que tan sólo veinte partidos de un total de 33 pudieron alcanzar el $6 \%$ de los sufragios expresados y beneficiarse, por tanto, del reparto de escaños en la Cámara de Representantes ${ }^{13}$. No obstante y a pesar del elevado número de votos recibidos, los nueve partidos restantes que no pudieron llegar al umbral establecido, recibieron 0 escaños. Por lo tanto, parece que en este momento comienza el preludio de la polarización del paisaje político, debido a la jurisprudencia de una institución que a pesar de su supuesto alejamiento de la opinión pública, ocupa el primer plano de la actualidad política desde el 2002: el Consejo Constitucional.

Más allá de la cuestión del Código Electoral, las elecciones del 2007 se desarrollaron bajo el auspicio de una nueva norma sobre partidos políticos que estableció, por primera vez, una serie de reglas relativa a la gestión y al funcionamiento democrático de los partidos, así como a su transparencia financiera. Dicha norma permitió, por lo tanto, un importante acercamiento a la situación de los países democráticos en el ámbito de la organización de los partidos políticos.

\section{La nueva norma de partidos}

Antes de la época constitucional en Marruecos, el Dahir del 15 de noviembre de 1958 garantizaba a todos los ciudadanos, entre otras libertades, la de formar parte de una organización sindical o política de su elección y asimilaba a los partidos con asociaciones de carácter político. El multipartidismo fue reconocido por la primera Constitución marroquí1 ${ }^{14}$. De hecho, si el Dahir del 15 de noviembre de 1958 (modificado en 2002) pretendía regular el espacio asociativo sin detallar las exigencias del funcionamiento ni la organización interna de los partidos, el texto supremo marroquí se limitó a garantizar el pluripartidismo simplemente mediante la prohibición del partido único (art. 3).

Por lo tanto, era indispensable una remodelación del marco jurídico que regulaba los partidos ya que de ello dependía «la racionalización, la renovación y la

13 Además de los 33 partidos, 2 alianzas y 13 listas independientes compitieron en las elecciones legislativas del 7 de septiembre.

${ }^{14}$ En su redacción inicial, (Constitución de 1962), el artículo 3 párrafo 1, precisa que «los partidos políticos contribuyen a la organización y a la representación de los ciudadanos. No puede existir, por tanto, un partido único». Desde 1970 (segunda convocatoria), otras instituciones sindicales, locales y profesionales participaron junto a los partidos en la representación y en la organización de la ciudadanía. 
inmunización del paisaje político marroquí» (discurso real de 8 de octubre de 2004). La respuesta al déficit normativo sobre partidos políticos se materializó en la ley n. ${ }^{\circ}$ 36-04, que entró en vigor en febrero de $2006^{15}$. La nueva norma de partidos respondió, de esta forma, a la necesidad de democratizar el funcionamiento así como la organización de los partidos políticos a la vez que conservaba, a semejanza de las normas de partidos en derecho comparado, el papel de las instituciones en la participación y gestión de los asuntos públicos ${ }^{16}$.

El nuevo texto ${ }^{17}$ garantiza una mejor representatividad, en el seno de las estructuras de partidos, y una mayor transparencia en la organización ${ }^{18}$ así como un mayor control de las finanzas del partido ${ }^{19}$. Sin embargo, lo más llamativo de la nueva norma de partidos es el espíritu subyacente de racionalización del terreno político que se desprende, en primer lugar, de las nuevas condiciones materiales y morales para la constitución de un partido político y, posteriormente, de la ratificación de la unión entre partidos quizás para hacer frente a la gran oferta partidista producida por la fragmentación del sistema de partidos $(\text { Szmolka Vida, I })^{20}$.

Se exige, por ejemplo, entre las condiciones materiales para la constitución de un partido, la presencia de 300 miembros fundadores residentes al menos la mitad en las regiones con un mínimo de 15 miembros por región, así como la celebración de un congreso fundador en un plazo de un año a partir de la fecha de recepción de la notificación de aprobación de la constitución del partido,

15 Ley n.o 36-04 Boletín Oficial n.o 5.400 de 02-03-2006 p. 334, la publicación del mismo texto en lengua árabe data de 20 de febrero de 2006, fecha de su entrada en vigor.

16 Para un estudio más detallado de la ley marroquí sobre partidos políticos, véase Amina El Messaoudi: 2007, «Participation et pluralisme dans la nouvelle loi des partis politiques», en Mélanges en hommage au professeur Jalal Essaid. Etudes juridiques, économiques et politiques. Najah Ljadida. Casablanca. Tomo 3, pp. 39-54.

17 Condiciones de constitución, de adhesión y procedimientos a seguir. La nueva ley impone que los estatutos del partido prevean un número proporcional de mujeres y jóvenes en las listas para las instancias dirigentes del partido (art. 22).

18 Por no citar más que un solo ejemplo, el partido político que no celebre un congreso durante cinco años pierde el derecho a recibir ayudas anuales del Estado (art. 40).

19 El Estado contribuye a la financiación de las campañas electorales y concede también una subvención anual para la cobertura del funcionamiento de los partidos en función de su representatividad parlamentaria y del número de votos obtenidos (art. 35). Los partidos políticos deben, en primer lugar, justificar la utilización de la cuantía recibida para los fines previstos (art. 36). Asimismo, deben estar en conformidad con las disposiciones del artículo 37 que somete el control de los gastos al Tribunal de Cuentas.

${ }^{20}$ Szmolka Vida Inmaculada: Fragmentación del sistema de partidos en Marruecos: análisis de la oferta partidista y del régimen electoral. (en prensa). 
emitida por el Ministro del Interior (art. 8 párrafo 3). Por lo tanto, para que el congreso constitutivo de un partido político sea válido, debe contar al menos con la presencia de 500 congresistas, de los cuales tres cuartas partes deben ser miembros fundadores, repartidos en función de su residencia efectiva en al menos la mitad de las regiones (art. 13).

Además de estas condiciones de naturaleza material, la ley fija también las condiciones de naturaleza moral. De hecho, se considera «de efecto nulo cualquier constitución de partido político fundada en una base religiosa, lingüística, étnica o regional o, de manera general, en cualquier condición discriminatoria o contraria a los derechos humanos» (art. 4).

Otras disposiciones de la ley 36-04, predisponen a la concentración del terreno político, sobre todo, a través de la consagración de todo un título de la ley a la unión de los partidos políticos y su fusión. De hecho y contrariamente a la legislación sobre asociaciones (Dahir de 1958 que regula el derecho de asociación tal y como fue modificado posteriormente), la nueva norma de partidos fomenta que los partidos políticos legalmente constituidos se organicen en uniones dotadas de personalidad jurídica, con objeto de obrar colectivamente a favor de la realización de objetivos comunes (art. 41). Junto a la unión entre los partidos, la nueva ley favorece también la fusión entre las formaciones políticas, dotándoles de los mismos derechos y obligaciones que al resto de las formaciones políticas (El Messaoudi, 2005: 19).

Por lo tanto, dos uniones participaron en los comicios de 2007. Se trata de la unión entre el Partido Nacional Demócrata (PND) y el Partido Al-Ahd, así como de la unión de tres grandes formaciones de izquierdas: el Partido Socialista Unificado (PSU), el Congreso Nacional Ittihadi (CNI) y el Partido de la Vanguardia Democrática Socialista (PADS). Las dos formaciones consiguieron 8 y 5 escaños respectivamente en los comicios del 7 de septiembre.

De todo lo anterior, se deduce que a partir de las reformas de las dos normas comienza a articularse la vida electoral y de partidos, así como una racionalización del paisaje político. De hecho, si 18 nuevos partidos surgieron entre 1998 y $2002^{21}$, tan

${ }^{21}$ En 1997, sólo había 18 partidos. En 1998, se reconoce el PJD, el partido islamista de Abdelkrim El Khatib. Asimismo, surgieron otros 11 partidos entre 2000 y 2002, entre ellos, el Movimiento de los Demócratas Independientes (MDI) de Mohamed Moujahid, en 2000, el Partido de la Reforma y del Desarrollo de Abderrahmane El Khouhen, el Partido Marroquí Liberal de Mohamed Ziane, la Unión Democrática de Bouazza Ikken, el Partido del Congreso Nacional Ittihadi de A.Bouzoubaa, el Partido de las Fuerzas Ciudadanas de Lahjouji. Otros cinco partidos nacieron durante el primer trimestre de 2002: la Alianza de las Libertadas de Ali Belhaj, el Partido Al Aâhd de N.Ouazzani, la Iniciativa Ciudadana por el Desarrollo de M.Benhammou, el Partido Liberal Reformador de M.Alouah y el Partido Attajdid wal Insaf de C. Achahbar. 
sólo cinco nuevos partidos vieron la luz entre 2002 y $2007^{22}$. Téngase en cuenta además que el umbral del 6\% de los sufragios emitidos necesario para el reparto de los escaños, favoreció la formación de bloques entre los partidos y alejó del juego legislativo a nueve partidos a nivel de las listas locales y veinte partidos a nivel de las listas nacionales.

Paralelamente a las modificaciones realizadas al arsenal jurídico en relación con los comicios, se consolidaron prácticas «institucionales» en las elecciones del 7 de septiembre como la cuota de mujeres, el control y la observación electorales, así como la afirmación de algunos mecanismos relativos a la formación y constitución del gobierno.

\section{Prácticas institucionales reconfortantes}

Aunque se ha destacado el impacto de algunas prácticas y procedimientos institucionales relativos a la formación de gobierno en Marruecos en un estudio anterior, (El Messaoudi y Vintró: 2005, 124-145), es importante destacar el peso de dos factores que, sin duda alguna, reforzaron la trascendencia de los comicios de 2007: la cuota femenina y la admisión del control y de la observación de elecciones.

\section{A) La cuota de mujeres}

Durante la sesión extraordinaria del Parlamento clausurada el 3 de abril de 2002, los diputados dieron muestra de una asistencia inhabitual durante el debate sobre el Proyecto de Ley Orgánica relativa a la elección de los miembros de la Cámara de Representantes. La cuota femenina, debatida anteriormente por las asociaciones de mujeres, dio lugar a la presentación de una lista nacional de

22 Se trata, en esta ocasión, del Partido de los Trabajadores (2006), del Partido del Renacimiento y de la Virtud (2006), del Partido Al badil Al Hadari (2005), de la Unión Marroquí para la Demacración (2006), del Partido Al Umma (2007) y del Partido de la Sociedad Democrática (2007). El número de partidos políticos en los comicios del 7-9-2007 fue de 33. Todos sin excepción se presentaron a las segundas elecciones del reinado de Mohamed VI. En tanto que partido reconocido, tan sólo el partido de la «Vía Democrática» decidió boicotear las elecciones de 2007, mientras que se elevaron a cinco los partidos e instancias políticas que boicotearon las elecciones legislativas de septiembre de 2002: el Partido de la Vanguardia Socialista (PAS), Nahj Dimocrati, (Vía democrática) el Movimiento Badil el Hadari, (Alternancia civilizacional) el Movimiento Amazigh y Al Haraka min ajli louma (Movimiento por la Nación). 
modo paralelo a las listas locales. Se reservó la primera lista al sexo femenino. Este último intento fue también objeto de un intenso debate entre las formaciones políticas. La pelota se encontraba de nuevo en el terreno del Consejo Constitucional que era quien debía aclarar si reservar una lista nacional en exclusiva para las mujeres, estaba de conformidad o no con el texto constitucional. El Consejo Constitucional declaró que la disposición relativa a la reserva explícita de 30 escaños para las mujeres era inconstitucional. De hecho, el artículo 8 de la Constitución no permite esta «discriminación» a favor de los hombres porque «el hombre y la mujer disfrutan de los mismos derechos políticos». Ante tal constatación, sólo un pacto de honor entre los partidos políticos a favor de la creación de una lista nacional femenina podía sacar a las mujeres de este callejón sin salida. Todos los partidos políticos se comprometieron a establecer una lista nacional que incluyera el nombre de treinta candidatas, de tal modo que se lograra una importante representación femenina en las legislativas.

Si analizamos las candidaturas femeninas durante las elecciones legislativas de septiembre de 2002, comprobaremos la existencia de profundos cambios. La representación de la mujer alcanzó el 10,8\%, es decir, 35 diputadas. Esta cifra sitúa a Marruecos en el puesto 92 (sobre 146) en la clasificación de parlamentos en términos de participación femenina y lo sitúa más allá de la media regional de la representación femenina en las Cámaras bajas, de los parlamentos árabes en especial, que es del $9,7 \%{ }^{23}$.

Dicho esto, la conservación de la cuota durante los comicios de 2007 pone en evidencia la buena voluntad de los diferentes actores políticos, necesaria en cualquier transición democrática. Subrayemos además que dicha medida no está basada en ninguna formalidad legal sino solamente en un acuerdo voluntario entre las partes.

El resultado electoral demostró que de los 33 partidos que competían en las elecciones de 2007, 26 presentaron listas nacionales reservadas en su totalidad a las mujeres ${ }^{24}$. De éstas, sólo seis listas que pertenecían a los «antiguos» partidos políticos se beneficiaron de escaños femeninos en el Parlamento. Se trata del Partido de Justicia y Desarrollo: 6 escaños, Partido del Istiqlal: 6 escaños, Unión Nacional de Independientes: 5 escaños, Movimiento popular: 5 escaños, Unión

${ }^{23}$ La media mundial de la representación femenina en los parlamentos es de 18,4\% en la primera cámara (cámara baja) , de 17,3\% en el senado ( cámara alta) o sea 18,2\% en las dos cámaras confundidas mientras que la media regional y precisamente de los Estados árabes es de 9,7\% en las cámaras bajas y de 7,0\% en los senados, es decir 9,1\% en las dos cámaras del Parlamento. Véase los datos de la Unión Interparlamentaria : situación al 31 de julio del 2008. (www.ipu.org)

${ }^{24}$ En 2002, 4 partidos habían presentado a hombres en las listas nacionales. 
Socialista de Fuerzas Populares: 5 escaños y 3 escaños para el Partido del Progreso y del Socialismo. Las listas nacionales de los veinte partidos restantes, como no llegaron al 6\% de los sufragios emitidos, no consiguieron ningún escaño. Treinta y cuatro mujeres consiguieron, por lo tanto, un escaño en la Cámara de Representantes, 30 de ellas resultantes de las listas nacionales y 4, de las listas locales ${ }^{25}$

De todos modos, quede constancia de que una lista reservada, aunque sea útil en una fase transitoria, también presenta sus riesgos. De hecho, esta práctica puede substituirse más tarde, por el sistema de alternancia de los candidatos de los dos sexos en la misma lista. Aunque la representación actual de la mujer marroquí en el Parlamento está lejos de ser satisfactoria (34 de 325, es decir, un $10,46 \%$ ), este logro es significativo, sobre todo, porque ha tenido lugar junto a la renovación de la elite femenina que ocupa los escaños durante la legislatura 2007-2012 26 .

Asimismo, no sólo se reforzó la presencia femenina en la institución legislativa sino que el gobierno que surgió tras las elecciones del 7 de septiembre, el gobierno El Fassi ${ }^{27}$, contaba, por primera vez en Marruecos, con siete (7) mujeres entre los 33 ministros, es decir, un 20,5\% del total de sus miembros. Téngase en cuenta además que cuatro de ellas ocupaban el cargo por primera vez ${ }^{28}$.

25 Se trata de Yasmina Baddou, elegida en la circunscripción de Casa-Anfa (partido del Istiqlal), de Latifa Jbabdi, en la circunscripción de Rabat Mouhit (Unión socialista de fuerzas populares), El Khiel Fatna, en la circunscripción de El Gharb, provincia de Kenitra (Movimiento Popular), y de Fatiha Llayadi, en la circunscripción de Rehamna, provincia de El Kelaa Des Sraghna (sin pertenencia política o SAP).

${ }^{26}$ En cuanto a las treinta nuevas diputadas, son en su mayoría nuevas figuras en el Parlamento. Es el caso de Aicha Guallaâ, una joven abogada elegida entre los miembros de la Chabiba de la USFP. También es el caso de Saloua Karkri Belakziz, ex presidente de la patronal de mujeres que fue gratificada por haberse sumado a las filas de la USFP. Asimismo, destacamos el caso de cinco mujeres que representan el RNI ya que son todas nuevas en el Parlamento. Entre ellas, se encuentra Najima Tay Tay, ex-secretaria de Estado para la alfabetización. Tres otras mujeres son empresarias y la quinta, dentista. Amal Omari, sindicalista de la UMT, es la última figura presentada por el PPS.

27 La mayoría gubernamental dirigida por Don Abbas El Fassi, está formada por cuatro formaciones políticas: el Partido del Istiqlal (PI), la Unión Nacional de los Independientes (RNI), la Unión Socialista de las Fuerzas Populares (USFP) y el Partido del Progreso y del Socialismo (PPS). El PI, además del Primer Ministro, dispone de 9 carteras. Le siguen el RNI (7), el USFP (5) y el PPS (2). Los SAP ascienden a 10.

${ }^{28}$ Recordemos que la primera vez que hubo una mujer en el gobierno marroquí fue en 1997. En ese momento, cuatro Secretarias de Estado «tecnócratas» hicieron su aparición. Aunque la representación femenina se ha reducido en número en los gobiernos posteriores, Youssoufi (1998) y Jettou ( 2002) (de cuatro a dos mujeres), ha progresado de categoría ministerial (de secretaria de 
La importancia de las prácticas institucionales en el proceso de formación del gobierno se desprende, también, de la realización de medidas que coronan el proceso electoral como las consultas reales con los líderes de los seis partidos políticos que habían obtenido más del $20 \%$ de los sufragios ${ }^{29}$ y el nombramiento poco después de un Primer Ministro, político y líder del partido con mejores resultados en las elecciones legislativas del 7 de septiembre de $2007^{30}$. El impacto del debate tras la declaración gubernamental presentada por el Primer Ministro ante el Parlamento ${ }^{31}$ se inscribe, además, entre estas prácticas institucionales apaciguadoras.

\section{B) Control y observación electoral}

Una de las grandes novedades del escrutinio de septiembre de 2007, fue la admisión por parte de los poderes públicos, de observadores tanto nacionales como internacionales ${ }^{32}$. La preocupación por garantizar la transparencia y la cre-

Estado a Ministra Delegada). En la actualidad, de las 7 mujeres que forman parte del gobierno Fassi, 5 son ministras y 2 secretarias de Estado. Éstas ocupan sectores ministeriales tan importantes como los de sus homólogos masculinos. A título de ejemplo, mencionados la Energía, la Cultura o la Sanidad, departamentos de crucial importancia en Marruecos.

${ }^{29}$ Se trata de Abbés El Fassi: Partido Istiqlal con 52 escaños, Saâd Eddine El Othmani: Partido de Justicia y Desarrollo con 46 escaños, Mahjubi Ahardane: Movimiento Popular con 41 escaños, Mutapha Mansouri: Unión Nacional de Independientes con 39 escaños, Mohamed El Yazghi: Unión Socialista de Fuerzas Populares con 38 escaños y Mohamed Abied: Partido de la Unión Constitucional con 27 escaños.

${ }^{30}$ Los resultados definitivos de las elecciones legislativas se anunciaron el 9 de septiembre de 2007 para las listas locales y el 10 de septiembre para las listas nacionales. El 13 de septiembre, el Rey recibió a los líderes de los seis primeros partidos políticos. El 19 de septiembre, nombró al Secretario general del partido del Istiqlal, Primer Ministro. Le encargó además que se encargara de las negociaciones para formar el próximo gobierno. Téngase en cuenta que ciertas de estas prácticas tienen, en otras experiencias democráticas, un rango constitucional. En Marruecos, es necesario destacar las premisas de una costumbre constitucional. Para más información, véase: Amina El Messaoudi y Juan Vintro 2005: Elecciones, partidos y Gobierno en Marruecos Ed. Tirant Lo Blanch. Valencia, pp. 119-145.

${ }^{31}$ La declaración gubernamental de Abbas El-Fassi, presentada ante la Cámara de Representantes el 24 de octubre de 2007, fue adoptada por 155 votos a favor, frente a 93 votos en contra y 7 abstenciones. Los grupos parlamentarios del PJD, del MP y de la UC votaron contra la declaración gubernamental que, sin embargo, fue apoyada por la USFP, el PPS, el RNI, así como por el grupo Assala Wa Mouassara del ex-Ministro Delegado del Interior, Fouad Ali El Himma.

32 Instancias nacionales e internacionales llevaron a cabo el control y la observación de la operación electoral de 2007 antes de la campaña electoral (del 13 de junio al 24 de agosto), durante la misma campaña electoral (del 25 de agosto al 6 de septiembre) y el mismo día de los comicios: El 7 de septiembre. 
dibilidad de las elecciones del 7 de septiembre explican la existencia de esta novedad.

La presencia de una misión de observación y de control electoral aporta una nueva prueba de la voluntad de las autoridades públicas a la hora de conferir una mayor credibilidad a esta nueva etapa democrática. El Rey lo dejó claro en su discurso del 20 de agosto de 2007, en el que declaró que «en efecto, no hay lugar para las prácticas ilegales en ningún ámbito ni sea quien sea el que las cometa. Juntos, debemos comprometernos en una lucha sin cuartel contra la corrupción y la prevaricación, el abuso de poder y de los bienes públicos, el feudalismo rentista, la rapiña y la práctica del reparto de botines. Esta lucha es responsabilidad de todos: autoridades, instituciones, ciudadanos y comunidades. Se trata de una acción de salubridad pública que debe inscribirse en el Estado de las instituciones, y éste, en la buena gobernanza.»

El colectivo asociativo para la observación de las elecciones ${ }^{33}$ veló, de hecho, por la transparencia del proceso electoral desde la fase de precampaña hasta la del recuento de votos el día del escrutinio, pasando por la campaña electoral. La misión de las asociaciones concernidas se comprometió a publicar los informes sobre el desarrollo de los comicios y, por lo tanto, se ha convertido en un actor importante en el proceso de democratización electoral.

De hecho, los primeros informes comenzaron a ver la luz. En primer lugar, el Foro Civil Democrático Marroquí (FCDM) publicó un informe el mismo día que se anunciaron los resultados definitivos de las elecciones ${ }^{34}$. Asimismo, se publicaron otros informes preliminares como el del Colectivo asociativo para la observación de las elecciones, el de la Organización Marroquí de Derechos Humanos (OMDH), el de Transparency Maroc, Democracy Reporting International, National Democratic Institut (NDI), etc.

En esta voluntad de transparencia, se inscribe la aparición de otros nuevos actores como el Consejo Consultivo de los Derechos Humanos (CCDH) y la Alta Autoridad del Consejo Superior de la Comunicación Audiovisual (HACA).

33 El colectivo asociativo para la observación de elecciones cuenta en sus filas con 617 asociaciones, 33 dirigentes y 3210 observadores voluntarios diseminados en las 16 regiones de Marruecos. Su misión consiste en detectar los hechos sospechosos o irregulares del acontecimiento electoral: precampaña, presentación de candidaturas, día de los comicios, etc.

${ }^{34}$ El FCDM organizó junto al Centro de Estudios y de Investigación en Ciencias Sociales, una conferencia de prensa el lunes 10 de septiembre de 2007 (tan sólo tres días después del día del escrutinio) para presentar sus impresiones y constataciones sobre el desarrollo de las elecciones del 7 de septiembre. El primer informe se hizo público el 8 de septiembre de 2007, al día siguiente de las elecciones. (Véase el diario Al Massae de 8 de septiembre de 2007). 
El Consejo Consultivo de Derechos Humanos (CCDH) que se encargó de supervisar la observación de este escrutinio, acreditó a una misión internacional compuesta por unos cincuenta miembros, así como por observadores nacionales representantes de la red asociativa.

Asimismo, fue la primera vez en la que una institución de regulación audiovisual interviene en una campaña electoral. La nueva función de la Instancia Nacional de Regulación (la HACA) en la organización y animación de la vida política durante el periodo electoral, se tradujo en diferentes contribuciones, sobre todo, en la constitución de comisiones de seguimiento del periodo electoral así como en la publicación de informes sobre el acceso en igualdad de condiciones a los medios de comunicación para los partidos políticos en campaña durante el escrutinio de $2007^{35}$.

Junto a la HACA, también es importante recordar el papel que han desempeñado otros medios de comunicación, tanto escritos como orales, en la movilización y la sensibilización de la sociedad para lograr un buen desarrollo de la jornada electoral de 2007. Los diferentes programas dedicados a las actividades así como a los programas de los partidos políticos antes y después de las elecciones del 7 de septiembre, reflejan la importancia que han tenido los medios de comunicación de masas durante el periodo electoral.

Por su parte, el Estado pasó de un intervencionismo electoral a una neutralidad positiva, tanto antes como después de la campaña electoral ${ }^{36}$. Por lo tanto, parece que los diversos actores políticos de las elecciones de 2007 apoyaron firmemente la apuesta por la transparencia.

No obstante, frente a los diversos aspectos en materia de gobernanza electoral, el desarrollo de las elecciones así como otros acontecimientos, conforman unas realidades electorales cuyo impacto se ha traducido, sin duda alguna, en una muy baja participación del electorado marroquí el día del escrutinio.

35 El 17 de julio de 2007, la HACA presenta en Rabat un primer informe relativo a la puesta en marcha de la decisión del CSCA (Consejo Superior de Comunicación Audiovisual) número 14.07 sobre el acceso en igualdad de condiciones y regular de los partidos políticos que participan en las elecciones legislativas de 2007 a los medios de comunicación.

36 Con el término «neutralidad positiva» se hace referencia al nuevo comportamiento de las autoridades estatales del cual se desprende que el Estado ya no «apoya» a un partido o a un candidato definidos, por lo tanto, permitiendo una lucha «libre» entre los partidos políticos y entre sus candidatos, la neutralidad del Estado en los comicios electorales es percibida como una posición positiva. 


\section{REALIDADES ELECTORALES}

A pesar de los esfuerzos realizados por el Estado con la nueva norma electoral para la instauración de una buena gobernanza para las elecciones del 7 de septiembre, las realidades políticas e institucionales sólo permiten ver «la punta del iceberg» y demuestran el débil y tímido impacto del «engennering» electoral.

Se trata, en concreto, de una serie de elementos que han desorientado y desequilibrado al electorado marroquí como, por ejemplo, el anuncio del Ministro Delegado del Interior de su candidatura a las elecciones del 7 de septiembre tras la presentación de su dimisión (1), la confluencia del paisaje político (2), y la la débil tasa de participación o la abstención (3).

\section{El giro inesperado}

Justo antes de la campaña electoral, se produjo un giro inesperado en el terreno político marroquí (Lopez García B, 2007) ${ }^{37}$ que desorientó a los líderes de los partidos políticos que ambicionaban llegar en cabeza de las elecciones para acceder al cargo de Primer Ministro, tal y como había prometido el Rey en su discurso en varias ocasiones.

¡Fouad Ali el-Himma, número dos del régimen, sin duda alguna el más cercano colaborador del Rey Mohammed VI, conmocionó al país y suscitó abundantes dudas al dimitir del cargo de Ministro Delegado del Interior, a principios de agosto, para presentar su candidatura ${ }^{38}$ ! La prensa no fue comedida. La entrada de Foud Ali El Himma, en la lucha electoral por la región de Erhamna, se consideró un preludio a su nombramiento al cargo de Primer Ministro. Sin embargo, la candidatura de Erhamna, difícilmente clasificable, estaba más bien destinada a la futura formación de un partido «fuerte» que ocupe el primer plano político en 2012. En otras palabras, si en la actualidad el nombramiento de Fouad Ali el-Himma como Primer Ministro tras las elecciones no parece ser un

37 La fórmula "giro inesperado» se la hemos tomado prestada a Bernabé García López de uno de sus comentarios sobre las elecciones del 7 de septiembre en Marruecos llamado «Un giro inesperado en la precampaña electoral» en el observatorio o Taller sobre los Estudios Internacionales en la Región Mediterránea (TEIM) de la Universidad Autónoma de Madrid. Los comentarios están disponibles en la página web de la Universidad: www.uam.es

38 Jefe de gabinete del Príncipe Heredero Sidi Mohammed desde octubre de 1998, el 9 de noviembre de 1999 es nombrado por el Rey Mohammed VI, Secretario de Estado de Interior. El 6 de septiembre de 2000, fue nombrado Ministro delegado del mismo Ministerio, cargo que ocupó hasta su dimisión el 8 de agosto de 2007. 
asunto de actualidad, son muchos los que consideran que su vuelta a la política dentro de dos o tres años ya está programada sobre todo después de las elecciones municipales de 2009. Esta hipótesis parece además ganar terreno si analizamos los antecedentes de la historia electoral marroquí.

Recordemos, en primer lugar, el caso del Primer Ministro, Ahmed Bahnini, quien tras haber ocupado diversos cargos ${ }^{39}$, presidió el primer gobierno constitucional marroquí de 18 de noviembre de 1963 (El Messaoudi A, 2001). Tras esta fecha, Bahnini creó el Partido Socialista Demócrata (PSD). Sin embargo, nos referimos sobre todo a Ahmed Reda Guédira, fundador del PSD, «uno de los intérpretes más auténticos del pensamiento real» (Sehimí M, 1996: 187) que ya había creado el Frente de Defensa de las Instituciones Constitucionales (FDIC) con sus colaboradores más cercanos (los liberales independientes). Las dificultades a las que tuvo que hacer frente el FDIC tras algunas contradicciones internas así como las diferencias surgidas entre Guédira y Aherdane del Movimiento Popular, le obligaron a dotarse de un instrumento «a medida», el Partido Socialista Demócrata (PSD) en abril-mayo de 1964. Esta última formación política consiguió posteriormente una representación importante en el gobierno Bahnini de 20 de agosto de 1964 (El Messaoudi, 2001: 178-181) ${ }^{40}$.

Unos diez años después, se da el caso de otro partido creado por Ahmed Osman, amigo de estudios del Rey Hassan II, en vísperas de la tercera legislatura marroquí, que ganó con el partido "Independientes» las legislativas de junio de $1977^{41}$ y que fue nombrado Primer Ministro el 10 de octubre del mismo año ${ }^{42}$. El Primer Ministro, Ahmed Osman, crea el 8 de octubre de 1978, el Reagrupamiento Nacional de los Independientes (RNI), partido que seguirá obteniendo la mayoría de los puestos ministeriales en el posterior gobierno de Maâti Bouabid en $1979^{43}$.

39 Firmante del manifiesto de independencia, Ahmed Bahnini ocupa el cargo de Secretario General del Ministerio del Interior y Ministro de la Justicia en enero de 1963.

40 De hecho, fue Ahmed Reda Guedira quien anunció la constitución del PSD tras las diferencias surgidas entre Mahjoudi Aherdane y Abderrahmane El Khatib (MP) sobre el partido Frente de Defensa de las Instituciones Constitucionales (FDIC). Ahmed Bahnini fue el Presidente del PSD y Ahmed Reda Guedira, su Secretario General. Seis (6) personalidades del PSD ocuparon cargos ministeriales en la remodelación del gobierno Bahnini con fecha de 20-08-1964. (El Messaoudi, 2001)

${ }^{41}$ De los 264 miembros de la Cámara de Representantes durante la tercera legislatura, el RNI obtuvo 141 escaños, es decir, el 53,40\%.

4211 cargos ministeriales se concedieron a personas de su propio partido en el gobierno Osman de 1977 y en el de Maâti Bouabid de 1979. (El Messaoudi, Ibid.)

43 Para más datos sobre la evolución del voto de los distintos partidos políticos marroquíes desde 1963 hasta 2002, ver Bernabé López García, 2005: «Marruecos virtual: reflexiones sobre las 
Tras estos ejemplos de partidos «fuertes», parece hábil la maniobra de Fouad Ali El Himma que se presentó a los comicios del 7 de septiembre en cabeza de lista independiente y que ganó 3 escaños. En suma, los «sin pertenencia política» (SAP) obtuvieron 81.364 votos, es decir, el 1,8\% ${ }^{44}$. El Himma hizo, de este modo, una entrada triunfal en el terreno político nacional, ya que sin partido político, logró formar un grupo parlamentario de 36 miembros y fue elegido jefe de la Comisión de la Defensa y de los Asuntos Extranjeros de la primera cámara del Parlamento. Además, muchos de sus colaboradores cercanos formaron parte de la coalición gubernamental de Abbas El-Fassi ${ }^{45}$.

Después de su entrada triunfal en el parlamento y llegando a formar grupos parlamentarios en sus dos Cámaras, El Himma consigue encaminarse a través de su asociación "Movimiento de todos los demócratas» hacia la constitución de su propio partido político que anuncia oficialmente el día 8 de agosto de 2008, bajo el nombre "Autenticidad y modernidad». Dicha formación política se hace con la fusión de cinco partidos políticos constituidos, en su mayoría, en vísperas de las elecciones legislativas de septiembre de $2002^{46}$.

\section{Ambigüedad del paisaje político}

Aunque el número de partidos políticos que participó en las elecciones legislativas del 7 de septiembre se elevaba a 33, el elector marroquí se enfrentó a una gran confusión en cuanto a la distinción entre partidos de derechas y de izquierdas y, sobre todo, entre partidos de la mayoría y aquéllos de la oposición. De hecho, los partidos políticos encarnan difícilmente las divisiones que estructuran la sociedad marroquí (Mounia bennani-Chraibi; 2005. p. 186).

elecciones 2002», en El Messaoudi A. y Vintro J. Elecciones, partidos y gobierno en Marruecos, op. cit. p. 79.

${ }^{44}$ Véanse los resultados de las elecciones legislativas de 7 de septiembre de 2007 en las siguientes páginas web: www.gov.legislatives2007.ma, www.map.ma

45 Jean Pierre Tuquoi: Le Monde de 17 de octubre de 2007.

46 Se trata de los partidos «Ahd» de Najib El Ouazzani creado en marzo 2002, del partido «Medioambiente y Desarrollo» ( PMAD) de Ahmed Alami creado en abril de 2002, de la "Alianza de Libertades» (ADL) de Ali Belhaj, creado en marzo de 2002, de la «Iniciativa ciudadana para el Desarrollo» (ICD) de Mohamed Benhammu creado también en marzo de 2002 y del «Partido Nacional Demócrata» de Abdellah Kadiri creado ya anteriormente, en 1982. Para más datos sobre los partidos políticos creados en vísperas de las elecciones 2002 véase la página web del ministerio de interior, citada ya anteriormente, y también la edición especial del semanal «La Vie Economique» de septiembre de 2002, p. 52. 
Téngase en cuenta que no tratamos de analizar la amplia oferta de partidos (Madani, 2006: 101), sino el fuerte parecido entre los partidos «importantes» que participaron en los comicios de 2007. De hecho, desde el acceso de los partidos del bloque democrático al poder (USFP, PI y PPS) en 1998, la oposición no se ha vuelto a ejercer de manera tan crítica como antes. Frente al pasado, existieron grandes similitudes entre las campañas electorales de los diferentes parti$\operatorname{dos}^{47}$, previas a los comicios del 7 de septiembre ${ }^{48}$.

En general, los partidos políticos adoptaron como temas principales de su campaña las preocupaciones principales de los ciudadanos marroquíes, es decir, el empleo, la educación, la sanidad, la vivienda, el desarrollo de la sociedad y la lucha contra la pobreza.

Sin embargo, salvo el Partido Socialista Unificado (PSU) que insistió en su programa electoral en las reformas políticas y constitucionales, existe una gran similitud entre los programas electorales y las intervenciones televisadas del resto de los partidos, sobre todo, en el caso de los partidos del bloque democrático (Kutla: USFP, PI y PPS) y el Partido de Justicia y Desarrollo (PJD).

De hecho, desde 2002, el Partido de Justicia y Desarrollo (PJD) que ejerce el papel de oposición, se ha preocupado poco por las cuestiones dialécticas e ideológicas que le diferencian de los partidos de la mayoría. El PJD ha mejorado de este modo considerablemente su influencia al entrar en los debates sobre las políticas públicas y las leyes necesarias para hacer frente a los problemas sociales y económicos de Marruecos. Su apertura a los grupos liberales y a los de izquierdas le ha permitido conquistar un importante apoyo popular en torno a la agenda de reforma nacional.

En su programa electoral, el PJD en lugar de referirse a la charia islámica como punto de referencia, menciona simplemente «la preservación de la identidad islámica de Marruecos». Esta afirmación también la había realizado el resto de partidos políticos que se presentaba a las elecciones del 7 de septiembre. Además, los principales temas durante la campaña electoral del partido de Jus-

${ }^{47} \mathrm{Al}$ analizar las escisiones entre partidos políticos, el historiador y escritor marroquí Abdellah Laroui habla de la «escisiparidad» de los partidos políticos marroquíes. Véase A.Laroui 2005.: Le Maroc et Hassan II. Un témoignage. Les Presses Inter Universitaires - Centre Culturel Arabe. pp. 236-237.

${ }^{48}$ Las doctrinas y las líneas políticas parecen diferenciarse dependiendo de los diferentes partidos políticos. Véase a tal efecto y, sobre todo, en relación con los partidos del Istiqlal y la Unión Socialista de Fuerzas Populares, María Angustias Parejo, 2006: «Los pesos pesados del maltrecho sistema de partidos políticos en Marruecos: PI y USFP», en Sociedad civil, derechos humanos y democracia en Marruecos. Carmelo Pérez Beltrán (ed.) Colección monográfica «Eirene» N. 22. Granada, pp. 69-113. 
ticia y Desarrollo no fueron los asuntos religiosos. Ciertos militantes criticaron esta omisión en el Consejo Nacional del PJD celebrado el 28, 29 y 30 de diciembre de 2007 y comenzaron a acusar a la dirección del partido de «liquidar la referencia religiosa a favor de una nueva identidad política de centro derecha» (L'Economiste 28-12-2007). Por consiguiente, parece que se está gestando una nueva política en el PJD con un referente religioso aunque sin "caer en ningún extremismo» (L'Economiste 31-12-2007).

Asimismo, existe otro acercamiento entre los partidos de los dos grandes bloques: mayoría y oposición. Se trata de dos ámbitos bien definidos y que figuran entre las demandas recurrentes de los partidos políticos en la precampaña electoral marroquí, es decir, el empleo y la gobernanza. De hecho, las cuestiones económicas y sociales destacaban en el programa electoral. Se trata, por lo tanto, de elaborar cifras sobre el número de empleos que se crearán a lo largo de la presente legislatura, así como la tasa de crecimiento y el índice de paro.

A título de ejemplo, la Unión Socialista de Fuerzas Populares propone la creación de dos millones de empleos durante la presente legislatura y un crecimiento económico del 7\%. Asimismo, el programa del partido Istiqlal contempla una reducción del índice del paro del 10 al 7\% así como la creación de 1.300 .000 empleos.

Por su parte, el Partido de la Justicia y del Desarrollo programa reducir el índice de paro al $10 \%$ y crear 1.500 .000 puestos de trabajo durante los cinco próximos años. El programa económico del PJD defiende también «una economía solidaria basada en la redistribución de las riquezas así como en la apertura a la empresa ciudadana ${ }^{49}$.

La similitud entre los partidos políticos, mayoría y oposición incluidas, se desprende también de la reivindicación de una reforma o gobernanza constitucional. De hecho, a través de un llamamiento a la rehabilitación del sistema de gobernanza, los partidos de la «Koutla» (USFP, PI, PPS) y los de la oposición (PJD, PSU) ponen de relieve en sus programas electorales la necesidad de una reforma constitucional. Ésta se basa, sobre todo, en el equilibrio entre los poderes mediante el refuerzo de las prerrogativas de las instituciones parlamentaria y gubernamental, en la independencia del "poder» judicial así como en la afirmación constitucional de la regionalización ampliada. Es decir, sobre todo, alcanzar un mayor grado de autonomía para las provincias del sur.

Teniendo en cuenta los datos mencionados, podemos afirmar que no existía una «fractura» entre la derecha y la izquierda, ni siquiera entre la mayoría y la oposición, en vísperas de los comicios. Por ello, los temas de campaña de los par-

\footnotetext{
49 Véase el programa electoral del PJD en la página web del partido: www.pjd.ma
} 
tidos políticos no eran muy variados lo que provocó, una mayor confusión entre los ciudadanos y reforzó la idea de que todos los partidos son iguales ${ }^{50}$. Pero, ¿Abdelkébir Khatibi no mencionaba ya en 1998 esta atomización de los partidos políticos? ${ }^{51}$ ¡El electorado marroquí se enfrentó por lo tanto a un terreno político más o menos ambiguo que induce a pensar que no existe un proyecto político consecuente claro ni una estrategia política en sí! Esta constatación se tradujo, evidentemente, el día de los comicios en una muy débil participación o, dicho de otro modo, en una elevada abstención.

\section{La abstención}

Se entiende, lógicamente, que la abstención no es una causa que desorientase al electorado marroquí durante el escrutinio del pasado 7 de septiembre, sino más bien un resultado que emana a su vez de otras causas políticas e institucionales. No obstante, el débil porcentaje de participación en los distintos comicios electorales de los años noventa deja planteado un temor general acerca del comportamiento electoral de los ciudadanos el día del escrutinio.

De hecho y teniendo en cuenta la diferencia de votos obtenidos por los partidos políticos entre 2002 y 2007, éstos tuvieron que asumir una gran parte de la responsabilidad por el descrédito que siente el electorado marroquí hacia la política en general, y las elecciones legislativas en particular. La disminución de la tasa de participación del 52\% al 37\% entre 2002 y 2007 nos lleva a plantearnos de nuevo cuáles son las razones directas e indirectas relacionadas con el fenómeno de la abstención.

El sondeo realizado entre el 28 de septiembre y el 11 de octubre de 2007 por el Gabinete LMS-CSA por cuenta de la asociación 2007 Daba, demuestra que los motivos principales que llevaron al 63\% de los marroquíes inscritos en las listas electorales a no votar en las legislativas del 7 de septiembre, fueron la falta de credibilidad de los candidatos, su poco interés por los asuntos que interesan a los ciudadanos y el incumplimiento de los compromisos electorales anteriores ${ }^{52}$. La Asociación 2007 Daba, a partir de las razones que ocasionaron la abstención y

50 «Los programas de los candidatos se parecen, no logro ver las diferencias» es una de las razones que esgrimía el 50\% de las personas entrevistadas por la asociación 2007 Daba. Véase L'Economiste de 25 de octubre de 2007, p. 36.

51 A. Khatibi, 1999: L'alternance et les partis politiques. EDDIF. p. 19.

52 La muestra se componía de 2.463 personas de los dos sexos mayores de edad, que viven en zonas urbanas y rurales y que están inscritas en las listas electorales. Véase L'Economiste de 25-102007, p. 36. 
basándose en dicho sondeo, llegó a la conclusión de que el 70\% de los marroquíes habían decidido no votar antes de la campaña electoral y que el 38\% ni la siguieron ${ }^{53}$. Esto prueba que el electorado ya estaba desinteresado mucho antes de los comicios. Por lo tanto, las elecciones de 2007 demostraron, una vez, más que el ciudadano marroquí no se interesa por este periodo de transición que no ha dado respuesta a sus principales expectativas ni a sus numerosas preocupaciones. La no inscripción en las listas electorales, el voto en blanco, el voto nulo $^{54}$ y la abstención o "el partido mayoritario de la abstención» (BennaniChraibi M, 2005: 163) ${ }^{55}$ ponen de relieve el descontento y la indiferencia política del electorado marroquí. Aunque se señala directamente con el dedo a los partidos políticos, el sistema en su totalidad figura entre las razones que fomentan la abstención el día de los comicios. Los abstencionistas no son sólo los «incompetentes electorales» sino también los decepcionados, los indiferentes y aquéllos que desconfían de la política oficial ${ }^{56}$.

Según las recomendaciones emitidas, de manera independiente, por el Colectivo Asociativo para la Observación de las Elecciones, Democracy Reporting Internacional (DRI), Transparency Maroc y la Organización Marroquí de Derechos Humanos (OMDH) sobre la gestión de las elecciones, es necesario un gran número de reformas para rehabilitar el acto electoral. A través de dichos informes, las diferentes ONG están de acuerdo en que es indispensable llevar a cabo una importante reforma política. Asimismo, se debería modificar el dispositivo normativo del siguiente modo: revisar la división electoral así como el modo de escrutinio.

En definitiva, la abstención no puede ir mano a mano con la transparencia. De hecho, la transparencia en sí no puede establecer la democracia ni la credibilidad del sistema electoral. Una credibilidad que, según ciertos observadores, conforma, en la actualidad, uno de los nuevos conceptos con los que el pueblo marroquí ha comenzado a familiarizarse ${ }^{57}$. Por consiguiente, el reto final consiste en fundar un

53 Ibid.

${ }^{54}$ La tasa de voto nulo alcanza el $19 \%$ para las listas locales y el 28,57\% para las listas nacionales. Véase la entrevista concedida por Bernabé López García a la revista Economía, publicada en la parte Estudios y sondeos, n. ${ }^{\circ}$, noviembre de 2007, pp. 72-74. La misma tasa fue de $15,55 \%$ en 2002 para las listas locales y de 17,15\% para las listas locales.

55 Sobre la abstención en las elecciones marroquíes de 2002: Mounia Bennani-Chraibi, 2005: «Actes de vote et d'abstention à Casablanca» en Scènes et coulisses de l'élection au Maroc. Les législatives 2002. Iremam-Kartala, pp. 163-186.

56 Ibid.

57 Hichem Ben Yaiche, 2008: «Les métamorphoses du Maroc», en L'Economiste de 4 de enero, pp. 34-35. 
ideal político en el que el ciudadano marroquí ponga su confianza. Tan sólo cuando se haya alcanzado ese objetivo, el electorado acudirá a las urnas y pondrá fin a una fase de desinterés político, que no es nuevo en la historia de Marruecos.

En definitiva, el cambio del dispositivo jurídico propuesto para las elecciones de 2007 ha resultado ser, una vez más, insuficiente para lograr una buena gobernanza electoral. Por lo tanto, tan sólo una verdadera cultura de la democracia permitirá la instauración de nuevas realidades electorales y favorecería el viento de aire fresco que comienza a soplar en Marruecos ${ }^{58}$.

\section{BIBLIOGRAFÍA}

BEN YAICHE HICHEM, 2008: Les métamorphoses du Maroc. L'Economiste du 4 janvier.

BENNANI-CHRAIBI MOUNIA (2005): «Actes de vote et d'abstention à Casablanca» in Scènes et coulisses de l'élection au Maroc. Les législatives 2002. Iremam-Kartala.

EL MESSAOUDI AMINA (2002), Nouveau cadre normatif et «assainissement» électoral. Elections 2002. Annuaire de l'Afrique du Nord 2002, CNRS, Paris, 2004. pp. 325-336.

—, (2007): «Participation et pluralisme dans la nouvelle loi des partis politiques» in Mélanges en hommage au professeur Jalal Essaid. Etudes juridiques, économiques et politiques. Najah Ljadida. Casablanca. Tome 3. pp. 39-54.

EL MESSAOUDI AMINA y JUAN VINTRO (2005): «Elecciones, partidos y Gobierno en Marruecos» Ed.; Tirant Lo Blanch. Valencia. España.

EL MESSAOUDI AMINA (2005): «A propos des Unions entre les partis politiques. Lecture dans le projet de loi sur les partis politiques». In Mensuel Dafatir Siyassiya, n. ${ }^{\circ} 74$, octobre, pp. 19-20.

—, (2001): «Les Ministres dans le système politique marocain». Najah El Jadida, Casablanca. (en árabe).

—, (2008): The road to transparency. In Morocco: Model or exception? Journal of Democracy. January, volume 19, Number 1, pp. 36-37.

INFORME DEL BANCO MUNDIAL (2003): Better Governance for Development in the Middle East and North Africa. Enhancing Inclusiveness and Accountabiliy. The world bank. Washington, D.C.

KHATIBI ABDELKEBIR (1999): L'alternance et les partis politiques. EDDIF.

LAROUI ABDELLAH (2005): Le Maroc et Hassan II. Un témoignage. Les Presses Inter Universitaires- Centre Culturel Arabe.

LÓPEZ GARCÍA, BERNABÉ (2000): «Marruecos político (cuarenta años de procesos electorales 1960-2000)» CIS, colección Monografías. N. 176, Madrid.

58 Ibid. 
—, 2005: Marruecos virtual: reflexiones sobre las elecciones 2002. In El Messaoudi A. y Vintro J. Elecciones, partidos y gobierno en Marruecos.

- (2007), Revue Economia, n. ${ }^{\circ}$ 1, Novembre.

MICHAEL McFAUL and TAMARA COFMAN WITTES (2008): Morocco's Elections. The limits of limited reforms. Journal of Democracy. January, volumu 19, Number 1, pp. 19-33.

MONTABES PEREIRA, JUAN (1999): «Las otras elecciones, Los procesos y sistema electorales en el Magreb». AECI, Madrid.

PAREJO FERNÁNDEZ, MARÍA ANGUSTIAS (1999), «El proceso electoral como indicador privilegiado de la transición tutelada en Marruecos» in Miscelánea de Estudios árabes y Hebráicos. Sección Ärabe-Islam. Vol. 48, Universidad de Granada.

—, (2006): «Los pesos pesados del maltrecho sistema de partidos politicos en Marruecos: PI y USFP» in Sociedad civil, derechos humanos y democracia en Marruecos. Carmelo Pérez Beltrán (ed.) Colección monográfica «Eirene» N. 22. Granada.

SEHIMI MUSTAPHA (1996): «GUEDIRA. Fidélité et engagement». Publisud. Okad. SZMOLKA VIDA, INMACULADA: Fragmentación del sistema de partidos en Marruecos: análisis de la oferta partidista y del régimen electoral. (en prensa) en Revista española de ciencia política.

TUQUOI, JEAN PIERRE (2007): Diario «Le Monde» 17 octubre.

WILLIAMSON, O.; (1996): The mechanisms of governance, Oxford, Oxford University Press.

Title

GOVERNANCE AND ELECTORAL REALITIES IN MOROCCO: THE LEGISLATIVE 2007.

\section{Summary}

INTRODUCTION. I. ELECTORAL GOVERNANCE. 1. The new electoral running defies. 2. The new parties regulations. 3. Comforting institutional practices. A. Female share. B. Control and observance of the electoral process. II. ELECTORAL REALITY. 1. An unexpected turn. 2. Ambiguity in the political scenery. 3. Abstention. BIBLIOGRAPHY.

\section{Resumen}

El objetivo de este trabajo es analizar las elecciones legislativas marroquíes de septiembre 2007 a través de una confrontación entre la gobernanza electoral desprendida del cambio del dispositivo normativo e institucional relativo al proceso electoral y entre unas realidades electorales que desorientaron al electorado marroquí. 
En primer lugar se analiza el impacto tanto de la reforma del código electoral como de la aparición de una nueva norma de partidos políticos sobre el desarrollo positivo o buena gobernanza de las elecciones. También se pone el énfasis sobre la voluntad estatal y política de ir en adelante a través del mantenimiento de ciertas prácticas como la cuota femenina y la observación electoral.

Por último se examina la ambigüedad del paisaje político en vísperas del escrutinio y el asombro resultado de la aparición de un nuevo candidato, «fuerte» en tanto que realidades electorales que desorientaron al final al electorado marroquí produciendo una alta y seria tasa de abstención.

\begin{abstract}
The main purpose in this work is to analyze the Moroccan legislative electoral process in September, 2007 through the confrontation of the electoral governance drawn from the changes performed in the new electoral and institutional regulations in relation to the electoral process and the electoral reality which confused the Moroccan electorate.

First, we will analyze the impact of both the electoral code reform and the new parties regulations on the positive development or a good governance of the election process. Then, we also stress the Moroccan Government's will to keep some electoral practices such as the female share and the electoral observance.

Finally, we will analyze the ambiguity in the Moroccan political scenery before the ballot and the astonishing result in which it arises a new and "strong" candidate under the perspective of the electoral reality which disoriented the Moroccan electorate and caused a high abstention rate.
\end{abstract}

\title{
Palabras clave
}

Elecciones. Marruecos. Dispositivo normativo. Gobernanza electoral. Practicas institucionales. Paisaje político.

\section{Key words}

Elections. Morocco. Electoral regulations. Electoral Governance. Institutional practices, Political scenery. 